\title{
COMPOSIČ̃̃O E ESTABILIDADE LIPÍDICA DA FARINHA DE ESPINHAÇO DE TILAPIA
}

\author{
Composition and lipid stability of tilapia fishbone flour
}

\author{
Maria Eugênia Petenuci', Flávia Braidotti Stevanato², Damila Rodrigues de Morais², \\ Leandra Pereira Santos ${ }^{2}$, Nilson Evelázio de Souza², Jesuí Vergílio Visentainer ${ }^{2}$
}

\begin{abstract}
RESUMO
Espinhaços de tilápias (Oreochromis niloticus) são partes do peixe de composição desconhecida. A composição lipídica dos espinhaços não é citada na literatura, bem como a estabilidade da farinha do espinhaço durante o armazenamento. Nesse sentido, realizou se estudo de processamento dos espinhaços envolvendo etapas de cocção, trituração, secagem, peneiramento e armazenamento da farinha. A farinha ficou armazenada sob refrigeração por um período de 90 dias, sendo sua qualidade monitorada por meio da composição em ácidos graxos, índice de acidez e análises microbiológicas. Os resultados da composição centesimal foram de 14,2\% (umidade), 40,8\% (proteína), 18,3\% (resíduo mineral fixo) e 25,3\% de lipídios totais. Nos lipídios totais foi identificado um total de 24 ácidos graxos, com predominância dos ácidos graxos (porcentagem média) de 27.4\% (ácido palmítico, 16:0), 35,15\% (ácido oléico, 18:1n-9) e 11,82\% (ácido linoléico, 18:2n-6) e, em menor proporção: 0,88\% (ácido alfa-linolênico, 18:3n-3), 0,08\% (ácido eicosapentaenóico, 20:5n-3) e 0,59 (ácido docosahexaenóico, 22:6n-3). Durante os 90 dias de armazenamento, foram observadas algumas alterações no índice de acidez e composição de alguns ácidos graxos, no entanto, para 60 dias de armazenamento, não foram observadas alterações na composição de nenhum ácido graxo, do índice de acidez e nas análises microbiológicas.
\end{abstract}

Termos para indexação: Tilápia, farinha, espinhaço, ácidos graxos, armazenamento.

\begin{abstract}
The composition of the tilapia (Oreochromis niloticus) fishbone is unknown. Lipid composition fishbone is not cited in the literature, and neither is the stability of the flour of the fishbone during storage. We studied the processing of fishbone cooking, grinding, drying, sieving and the storage of the flour. The flour was stored in a refrigerator for a period of 90 days, and its quality was monitored through fatty acid composition, acid index and microbiology control. The results of the proximate composition were of $14.2 \%$ (moisture), $40.8 \%$ (protein), $18.3 \%$ (ash), and $25.3 \%$ total lipids. In the total lipids identified 24 fatty acids were identified, with predominance of the fatty acids (medium percentage) of 27.4\% (palmitic acid, 16:0), 35.15\% (oleic acmid, 18:1n-9) and $11.82 \%$ (linoleic acid , 18:2n-6) and, in smaller proportion: $0.88 \%$ (alpha-linolenic acid, 18:3n-3), 0.08\% (eicosapentaenoic acid, 20:5n-3) and 0.59 (docosahexaenoic acid, 22:6n-3). During the 90 days of storage some alterations were observed in the acid index and composition of some fatty acids, however, for 60 days of storage no alterations were observed in the fatty acids composition, acid index, and microbiology control.
\end{abstract}

Index terms: Tilapia, flour, backbone, fatty acids, storage.

(Recebido em 21 de fevereiro de 2008 e aprovado em 16 de fevereiro de 2009)

\section{INTRODUÇÃO}

Atualmente, o Brasil é o quarto maior exportador de filés de tilápia [Oreochromis niloticus (L.)] para os Estados Unidos, com uma produção aproximada de 2.100 ton./ano. Entretanto, com o aumento da produção de filés cresce também a quantidade de resíduos gerados que, no caso da tilápia do Nilo, representa aproximadamente $66 \%$ do peixe (Souza \& Maranhão, (2001). Tais subprodutos que envolvem a cabeça, nadadeiras, vísceras e espinhaço, são normalmente descartados no meio ambiente, ocasionando poluição orgânica.
Segundo alguns autores, diversos produtos podem ser produzidos a partir dos resíduos gerados pelas indústrias processadoras de pescado, além da farinha e do óleo bruto, tais como concentrados protéicos, surimi, patês, farinha de peixe e silagem, entre outros (Morales-Ulloa \& Oetterer, 1995; Bimbo, 2000).

Estudos demonstram a importância dos ácidos poli-insaturados ômega-3 (n-3 PUFAs) como os ácidos alfalinolênico (LNA, 18:3n-3), eicosapentaenóico (EPA, 20:5n-3) e docosahexaenóico (DHA, 22:6n-3) na prevenção de doenças cardiovasculares, como arteriosclerose, além de atuar no sistema imunológico e

1Universidade Estadual de Maringá/UEM - Departamento de Química - Campus Universitário Maringá - Avenida Colombo - 5790 - 87020 -900 - Maringá, PR mapetenuci@hotmail.com

²Universidade Estadual de Maringá/UEM - Departamento de Química - Maringá, PR 
em processos anti-inflamatórios, principalmente, em casos de asma, artrite reumatóide e autoimunidade (Stansby, 1990; Badolato et al., 1991).

Por outro lado, o conteúdo lipídico dos peixes é suscetível à deterioração, em razão da rapidez com que o processo de autoxidação ocorre quando PUFAS são expostos ao ar (Stansby, 1990). Nessa degradação, há formação de produtos como aldeídos, cetonas, ácidos, alcoóis e hidrocarbonetos, responsáveis pelas características organolépticas e físico-químicas associadas com a rancificação (Hasenhuettl \& Wan, 1992) e, desta forma, afetando a qualidade do produto, tornando-o impróprio para consumo. Além disso, a proliferação de bactérias também contribui para a putrefação do pescado, sendo que Pseudomonas, Micrococcus, Flavobacterium, Serratia e Bacillus podem produzir toxinas que comprometem de maneira irreversível a qualidade do produto, enquanto coliformes fecais, Salmonella e Staphylococcus, estão, intimamente, associadas às condições higiênicas de manipulação (Oetterer, 2002).

Por fim, nota-se que as cabeças, nadadeiras, vísceras e espinhaços podem ser utilizados para a produção de alimentos nutritivos e de baixo custo, sendo uma alternativa viável de exploração comercial e ambiental, pois diminui a disposição dessas fontes de poluição orgânica no meio ambiente. Desse modo, este estudo objetivou a produção de farinha a partir de espinhaços de tilápia e, principalmente, avaliar o processamento, monitorar a estocagem, a composição química e de ácidos graxos da farinha por um período de 90 dias.

\section{MATERIAL E MÉTODOS}

\section{Preparo da Farinha de Espinhaços}

Foram coletados 40 espinhaços de tilápia de pesqueiro localizado no Norte do Estado do Paraná PR. Procedeu-se, o cozimento a vapor durante 25 minutos com água a temperatura aproximada de $100{ }^{\circ} \mathrm{C}$, seguido de trituração em moinho de aço inox (rosca sem fim). Posteriormente, a massa obtida foi disposta em assadeiras e levada ao forno (fogão comercial), onde permaneceu por 4 horas a $180^{\circ} \mathrm{C}$. O produto obtido foi então peneirado em peneiras de aço inox 14 mesh e, dessa forma, obteve-se a farinha de espinhaços de tilápia (FET). A farinha obtida foi armazenada em sacos de polietileno, o ar removido e estes envolvidos com papel alumínio e mantidos sob refrigeração $\left(4^{\circ} \mathrm{C}\right)$ por um período 90 dias de armazenamentos e as análises realizadas a cada 30 dias.

\section{Composição e Controle de Qualidade}

As análises de umidade, cinzas e proteína bruta foram realizadas segundo técnicas da AOAC (Cuniff, 1998) e os lipídios extraídos pelo método descrito por Bligh \& Dyer (1959).

A instabilidade lipídica foi monitorada (pela composição em ácidos graxos), no tempo zero e a cada 30 dias até se completar o período de 90 dias. Foram usados como indicadores: o índice de acidez (Moretto et al., 2002); e análises microbiológicas pela Food and Drug Administration - FDA (1995) com contagem total de bactérias mesófilas, número mais provável de coliformes totais e fecais, bem como, pesquisa de Salmonella spp. e contagem de Bacillus cereus. A composição em ácidos graxos nos lipídios totais, foi realizada segundo procedimentos de Joseph \& Ackaman (1992) com todas as etapas realizadas sob atmosfera de $\mathrm{N}_{2}$ gasoso.

Análises cromatográficas dos metil ésteres foram separados em cromatógrafo gasoso 14-A (Simadzu, Japan), equipado com detector de ionização de chama e coluna capilar de cianopropil (100 m de comprimento, 0,25 mm de diâmetro interno e 0,25 $\mu \mathrm{m}$ de CP-7420 Varian, EUA). O fluxo de $\mathrm{H}_{2}$ (gás de arraste) na coluna foi de $1,0 \mathrm{~mL} / \mathrm{min}$, com $30 \mathrm{~mL} / \mathrm{min}$ de $\mathrm{N}_{2}$ (make up); e de 30 e $300 \mathrm{~mL} / \mathrm{min}$, para o $\mathrm{H}_{2}$ e ar sintético respectivamente, para a chama do detector. O volume injetado foi de 1,0 $\mu \mathrm{L}$, utilizando "split" $1: 80$, sendo as temperaturas do injetor e detector de $220 \mathrm{e}$ $240^{\circ} \mathrm{C}$, respectivamente, enquanto a coluna de $165^{\circ} \mathrm{C}$ durante 18 minutos é elevada a $235^{\circ} \mathrm{C}$ com taxa de $4^{\circ} \mathrm{C} / \mathrm{min}$, mantida por 24,5 minutos. A identificação dos ácidos graxos foi efetuada por meio da comparação dos tempos de retenção com padrões Sigma (EUA) e, as concentrações determinadas por meio da integração das áreas dos picos pelo Software Varian Workstation Star, versão 5.0.

\section{Análises Estastísticas}

Os resultados foram submetidos á análise de variância (ANOVA) a 5\% de probabilidade, pelo teste de Tukey, por meio do programa Statistica, versão 5,0 (STATSOFT, 1995).

\section{RESULTADOS E DISCUSSÃO}

$\mathrm{Na}$ Tabela 1, apresentam-se os dados da composição química da farinha do espinhaço de tilápia (FET) no tempo zero. Observa-se que os teores de umidade, cinzas e proteína foram de $14,2 \%, 18,3 \%$ e $40,8 \%$, respectivamente, enquanto teor de lipídios totais foi de $25,3 \%$. Esses resultados indicam que a farinha do espinhaço apresenta elevado teor de minerais, além disso, é uma excelente fonte calórica e protéica. 
Tabela 1 - Composição química aproximada da farinha do espinhaço da tilápia no tempo zero.

\begin{tabular}{cc}
\hline Composição $(\%)$ & Farinha do espinhaço (FET) \\
\hline Umidade & $14,2 \pm 0,10$ \\
Resíduo Mineral Fixo & $18,3 \pm 0,08$ \\
Proteína Bruta & $40,8 \pm 0,15$ \\
Lipídios Totais & $25,3 \pm 0,16$ \\
\hline
\end{tabular}

Valores das médias com seus desvios padrão. As análises foram realizadas em triplicata.

A composição em ácidos graxos em percentagem relativa da FET no tempo zero e durante o armazenamento por 30, 60 e 90 dias é apresentada na Tabela 2, juntamente com o somatório de ácido graxos poli-insaturados (AGPI), monoinsaturados (AGMI), saturados (AGS), série ômega6 (n-6), série ômega-3 (n-3) e das razões dos ácidos graxos AGPI/AGS e n-6/n-3.

Foi encontrado um total de 24 ácidos graxos nos lipídios totais para a FET no tempo zero e durante o armazenamento, sendo a predominância dos ácidos graxos palmítico (16:0), oléico (18:1n-9) e linoléico (18:2n-6), com teores médios de $27,4 \%, 35,15 \%$ e $11,82 \%$, respectivamente. Esses ácidos graxos também foram predominantes na fração lipídica encontrada por Stevanato et al. (2007) em farinhas de cabeças de tilápia, por Souza et al. (2008) e Tonial et al. (2009) em filés de tilápia sob dieta prolongada.

Na Tabela 2, observa-se que o DHA apresentou uma tendência de redução insignificante ou longo do período de estocagem, enquanto 14:0, 15:0 e LNA também diminuíram, mas com diferença significativa ocorrida aos 90 dias de estocagem. Porém, não houve diferença significativa nos somatórios de AGPI, AGMI, AGS, n-6 e n-3 e mesmo entre as razões AGPI/AGS e n-6/n-3, durante os três meses de avaliação do estudo, mostrando a estabilidade dos ácidos graxos sob refrigeração.
A razão de AGPI/AGS inferior a 0,45 indicam alimentos pouco saudáveis, especialmente em relação às doenças cardiovasculares (Department of Health and Social Security, 1984). O valor encontrado da razão AGPI/AGS foi de 0,41 no tempo zero e 0,40, após 90 dias de armazenamento. Esse valor foi próximo ao encontrado por Stevanato et al. (2007) em farinha de cabeças de tilápias $(0,47)$.

A razão de ácidos graxos n-6/n-3 foi de 8,56 no tempo zero e 9,20 após 90 dias de armazenamento. Esses valores encontrados para razão n-6/n-3 foram acima de 4, cujo valor é recomendado nutricionalmente (Report on Health and Social Subjects - HMSO, 1994), entretanto, estão dentro da faixa assinalada por Simopoulos et al. (1999), que é de 5 a 10.

Os valores obtidos na análise de índice de acidez (IA, em mg de KOH/g de FET) são apresentados na Tabela 2. Observa-se que as médias apresentaram uma tendência crescente, mas diferença significativa ocorreu apenas aos 90 dias de estocagem. De acordo com a Associação Nacional dos Fabricantes de Alimentação Animal - Anfal (1998), farinhas de carne e ossos devem apresentar no máximo $4 \mathrm{mg}$ de $\mathrm{KOH} / \mathrm{g}$ de amostra, assim sendo, os valores encontrados estão dentro do padrão estabelecido.

Na Tabela 3, mostram-se os resultados das análises microbiológicas na farinha de espinhaço de Tilápia no tempo zero e durante os 90 dias de armazenamento.

Nota-se que não houve alteração microbiana na FET no tempo zero e no final do armazenamento. Além disso, as bactérias mesófilas estão dentro dos padrões aceitáveis, com valores menores que $10^{6} \mathrm{UFC} / \mathrm{g}$, conforme descrito por Lira et al. (2001), enquanto que as contagens para bactéria Salmonella spp., coliformes fecais a $45^{\circ} \mathrm{C}$, coliformes totais, bem como ausência de Salmonella, estão dentro dos padrões para produtos derivados de pescado pré-cozido (Agência Nacional de Vigilância Sanitária ANVISA, 2001). 
Tabela 2 - Composição em ácidos graxos e acidez na farinha do espinhaço de tilápia (FET) nos diferentes tempos de armazenamento.

\begin{tabular}{|c|c|c|c|c|}
\hline Fatty acids* & Tempo zero & 30 dias & 60 dias & 90 dias \\
\hline $12: 0$ & $0,40 \pm 0,01 a$ & $0,42 \pm 0,01 \mathrm{a}$ & $0,40 \pm 0,01 \mathrm{a}$ & $0,40 \pm 0,01 \mathrm{a}$ \\
\hline $14: 0$ & $2,89 \pm 0,18 \mathrm{a}$ & $3,02 \pm 0,27 \mathrm{a}$ & $3,18 \pm 0,23 \mathrm{a}$ & $3,66 \pm 0,02 b$ \\
\hline $14: \ln 5$ & $0,15 \pm 0,01 a$ & $0,14 \pm 0,03 \mathrm{a}$ & $0,17 \pm 0,01 \mathrm{a}$ & $0,21 \pm 0,03 a$ \\
\hline $15: 0$ & $0,22 \pm 0,01 \mathrm{a}$ & $0,23 \pm 0,02 \mathrm{a}$ & $0,23 \pm 0,01 \mathrm{a}$ & $0,27 \pm 0,01 b$ \\
\hline $16: 0$ & $27,18 \pm 0,32 \mathrm{a}$ & $27,89 \pm 1,32 \mathrm{a}$ & $27,20 \pm 0,33 a$ & $27,35 \pm 0,26 a$ \\
\hline $16: 1 n-7$ & $5,03 \pm 0,34 \mathrm{a}$ & $4,98 \pm 0,82 \mathrm{a}$ & $5,83 \pm 0,02 \mathrm{a}$ & $5,93 \pm 0,06 a$ \\
\hline $17: 0$ & $0,34 \pm 0,01 a$ & $0,35 \pm 0,03 a$ & $0,33 \pm 0,01 \mathrm{a}$ & $0,35 \pm 0,01 \mathrm{a}$ \\
\hline $17: 1 \mathrm{n}-7$ & $0,28 \pm 0,04 a$ & $0,27 \pm 0,03 \mathrm{a}$ & $0,31 \pm 0,01 \mathrm{a}$ & $0,32 \pm 0,03 \mathrm{a}$ \\
\hline 18:0 & $7,51 \pm 0,58 \mathrm{a}$ & $7,56 \pm 0,40 \mathrm{a}$ & $7,19 \pm 0,11 \mathrm{a}$ & $7,43 \pm 0,46 a$ \\
\hline $18: 1 n-9$ & $35,80 \pm 1,28 \mathrm{a}$ & $35,27 \pm 1,17 \mathrm{a}$ & $35,34 \pm 0,58 \mathrm{a}$ & $34,19 \pm 0,50 \mathrm{a}$ \\
\hline $18: 1 \mathrm{t} 9$ & $0,45 \pm 0,02 \mathrm{a}$ & $0,69 \pm 0,25 a$ & $0,43 \pm 0,00 \mathrm{a}$ & $0,44 \pm 0,06 a$ \\
\hline $18: 2 \mathrm{t} 9 \mathrm{t} 12$ & $0,13 \pm 0,01 \mathrm{a}$ & $0,13 \pm 0,01 \mathrm{a}$ & $0,13 \pm 0,01 \mathrm{a}$ & $0,07 \pm 0,01 \mathrm{a}$ \\
\hline $18: 2 n-6$ & $11,74 \pm 0,69 a$ & $11,44 \pm 0,72 \mathrm{a}$ & $12,13 \pm 0,16 a$ & $11,98 \pm 0,50 \mathrm{a}$ \\
\hline $18: 3 n-6$ & $0,81 \pm 0,08 \mathrm{a}$ & $0,79 \pm 0,07 \mathrm{a}$ & $0,85 \pm 0,03 \mathrm{a}$ & $0,86 \pm 0,05 a$ \\
\hline $18: 3 n-3$ & $0,94 \pm 0,08 \mathrm{a}$ & $0,92 \pm 0,08 \mathrm{a}$ & $0,88 \pm 0,04 a$ & $0,78 \pm 0,02 b$ \\
\hline $20: 1 n-9$ & $2,17 \pm 0,23 a$ & $2,17 \pm 0,16 a$ & $2,01 \pm 0,01 \mathrm{a}$ & $1,89 \pm 0,24 \mathrm{a}$ \\
\hline $21: 0$ & $0,17 \pm 0,02 \mathrm{a}$ & $0,17 \pm 0,02 \mathrm{a}$ & $0,15 \pm 0,01 \mathrm{a}$ & $0,18 \pm 0,04 \mathrm{a}$ \\
\hline $20: 2 n-6$ & $0,80 \pm 0,30 \mathrm{a}$ & $0,83 \pm 0,22 \mathrm{a}$ & $0,48 \pm 0,15 \mathrm{a}$ & $0,51 \pm 0,01 \mathrm{a}$ \\
\hline $20: 3 n-6$ & $0,56 \pm 0,01 \mathrm{a}$ & $0,56 \pm 1,51 \mathrm{a}$ & $0,60 \pm 0,06 a$ & $0,64 \pm 0,02 \mathrm{a}$ \\
\hline $22: 1 n-9$ & $1,31 \pm 0,07 \mathrm{a}$ & $1,27 \pm 0,08 \mathrm{a}$ & $1,23 \pm 0,18 \mathrm{a}$ & $1,21 \pm 0,12 \mathrm{a}$ \\
\hline $20: 4 n-6$ & $0,05 \pm 0,01 \mathrm{a}$ & $0,05 \pm 0,01 \mathrm{a}$ & $0,05 \pm 0,00 \mathrm{a}$ & $0,08 \pm 0,04 \mathrm{a}$ \\
\hline $20: 5 n-3$ & $0,05 \pm 0,01 \mathrm{a}$ & $0,04 \pm 0,01 \mathrm{a}$ & $0,03 \pm 0,00 \mathrm{a}$ & $0,18 \pm 0,14 \mathrm{a}$ \\
\hline $24: 1 n-9$ & $0,74 \pm 0,10 \mathrm{a}$ & $0,71 \pm 0,08 \mathrm{a}$ & $0,65 \pm 0,04 a$ & $0,62 \pm 0,03 a$ \\
\hline $22: 6 n-3$ & $0,64 \pm 0,08 \mathrm{a}$ & $0,59 \pm 0,10 \mathrm{a}$ & $0,57 \pm 0,03 \mathrm{a}$ & $0,57 \pm 0,03 \mathrm{a}$ \\
\hline AGPI & $15,72 \pm 3,76$ & $15,35 \pm 3,67$ & $15,72 \pm 3,91$ & $15,67 \pm 3,85$ \\
\hline AGMI & $46,67 \pm 12,25$ & $46,21 \pm 12,06$ & $46,62 \pm 12,10$ & $45,43 \pm 11,70$ \\
\hline AGS & $38,71 \pm 9,91$ & $39,64 \pm 10,17$ & $38,68 \pm 9,90$ & $39,64 \pm 9,94$ \\
\hline$n-6$ & $13,96 \pm 5,01$ & $13,67 \pm 4,88$ & $14,11 \pm 5,21$ & $14,07 \pm 5,13$ \\
\hline$n-3$ & $1,63 \pm 0,45$ & $1,55 \pm 0,44$ & $1,48 \pm 0,43$ & $1,53 \pm 0,30$ \\
\hline AGPI/AGS & 0,41 & 0,39 & 0,41 & 0,40 \\
\hline$n-6 / n-3$ & 8,56 & 8,56 & 9,53 & 9,20 \\
\hline IA** & $0,91 \pm 0,01 \mathrm{a}$ & $1,00 \pm 0,01 \mathrm{a}$ & $1,09 \pm 0,02 \mathrm{a}$ & $1,19 \pm 0,04 b$ \\
\hline
\end{tabular}

*Médias (expressas em \% de área relativa) com as respectivas estimativas do desvio padrão. ** Médias expressas em mg de $\mathrm{KOH} / \mathrm{g}$ de amostra As análises foram realizadas em triplicatas. Letras diferentes na mesma linha indicam diferenças significativas ( $<<0,05)$. Abreviações: AGPI (Somatório dos Ácidos Graxos Polinsaturados), AGMI (Ácidos Graxos Monoinsaturados), AGS (Ácidos Graxos Saturados), n-6 (Ácidos graxos da Família n-6), n-3 (Ácidos Graxos da Família n-3) e também razões de AGPI/ AGS (razão entre o somatório do ácidos graxos poli-insaturados e saturados) n-6/n-3 (razão entre o somatório dos ácidos graxos n-6 e n-3). IA (Índice de acidez) 
Tabela 3 - Resultados das análises microbiológicas realizadas na farinha de espinhaço de tilápia no tempo zero e aos 90 dias de estocagem.

\begin{tabular}{|c|c|c|}
\hline & Tempo zero & 90 dias \\
\hline Bactérias Mesófilas (UFC/g) & $3 \times 10^{4}$ & $3 \times 10^{4}$ \\
\hline Coliformes Totais (NMP/g) & $<3$ & $<3$ \\
\hline Coliformes de Origem Fecal a $45^{\circ} \mathrm{C}(\mathrm{NMP} / \mathrm{g})$ & $<3$ & $<3$ \\
\hline Salmonella spp. em $25 \mathrm{~g}$ & Ausente & Ausente \\
\hline Bacillus cereus (UFC/g) & $<1 \times 10^{2}$ & $<1 \times 10^{2}$ \\
\hline
\end{tabular}

Valores expressos em UFC/g (Unidade Formadora de Colônia por grama); NMP/g (Número Mais Provável por grama). As análises foram realizadas pelo Laboratório de Microbiologia e Microscopia de Alimentos do Departamento de Análises Clínicas da Universidade Estadual de Maringá.

\section{CONCLUSÕES}

A farinha do espinhaço de tilápia apresentou elevado teor de resíduo mineral fixo, proteínas e de lipídios totais, constituindo, assim, um alimento protéico e altamente calórico. Os teores de ácidos graxos ômega-3 e de poli-insaturados na farinha foram considerados baixos. Os parâmetros de estabilidade utilizados e a composição em ácidos graxos não indicaram alterações até 60 dias de armazenamento.

\section{REFERÊNCIAS BIBLIOGRÁFICAS}

AGÊNCIA NACIONAL DE VIGILÂNCIA SANITÁRIA.

Resolução RDC no 12, de 2 de janeiro de 2001.

Regulamento técnico sobre padrões microbiológicos

para alimentos. Brasília, 2001. Disponível em:

UWww.anvisa.gov.bri ’. Acesso em: 18 ago. 2005.

\section{ASSOCIAÇÃO NACIONAL DOS FABRICANTES DE} ALIMENTAÇÃO ANIMAL. Compêndio brasileiro de alimentação animal. São Paulo: ANFAR/CBNA/SDR, 1998.

BADOLATO, E.S.G.; CARVALHO, J.B.; TAVARES, M. Determinação do ácidoeicosapentaenóico (EPA) em óleo de sardinha (Sardinella brasiliensis) brasileira e em suplementos alimentares à base de óleo de sardinha. Revista do Instituto Adolfo Lutz, São Paulo, v.51, n.1/2, p.75-81, 1991.

BIMBO, A.P. Fish meal and oil. In: MARTIN, R.E.; ARTER, E.P.; FLICK JUNIOR, G.J.; DAVIS, L.M. (Ed.). Marine \& Freshwater products handbook. Lancaster: Technomic, 2000. p.541-582, 964p.

BLIGH, E.G.; DYER, W.J. A rapid method of total lipid extraction and purification. Canadian Journal of
Biochemistry and Physiology, Ontario, v.37, p.911-917, 1959.

CUNIFF, P.A. Official methods of analysis of AOAC international. 16.ed. Arlington, 1998. CD-ROM.

DEPARTMENT OF HEALTH AND SOCIAL SECURITY. Diet and cardiovascular disease. Meat Science, London, v.42, p.443-456, 1984.

FOOD AND DRUG ADMINISTRATION.

Bacteriological analytical manual. 8.ed. Washington: AOAC International, 1995.

HASENHUETTL, G.L.; WAN, P.J. Temperature effects on the determination of oxidative stability with the metrohm rancimat. Journal of American Oil Chemists' Society, v.69, n.6, p.525-527, June 1992.

JOSEPH, J.D.; ACKAMAN, R.G. Capillary column gas chromatography method for analysis of encapsulated fish oil and fish oil ethyl esters: collaborative study. Journal of AOAC International, Washington, v.75, p.488-506, 1992.

LIRA, G.M.; PEREIRA, W.D.; ATHAYDE, Á.H. Avaliação da qualidade de peixes comercializados na cidade de Maceió, AL. Revista Higiene Alimentar, São Paulo, v.15, n.84, p.67-74, maio 2001.

MORALES-ULLOA, D.F.; OETTERER, M. Bioconversão de resíduos da indústria pesqueira. Ciência e Tecnologia de Alimentos, Campinas, v.5, n.3, p.206-214, 1995.

MORETTO, E.; FETT, R.; GONZAGA, L.V.; KUKOSKI, E.M. Introdução à ciência de alimentos. Florianópolis: UFSC, 2002. 255p. 
OETTERER, M. Industrialização de pescado cultivado. Guaíba: Agropecuária, 2002.

REPORT ON HEALTHAND SOCIAL SUBJECTS. Department of Health. Nutritional aspects of cardiovascular disease. London, 1994.

SIMOPOULOS, A.P.; LEAF, A.; SALEM, N. Essentially and recommended dietary intakes for omega- 6 and omega-3 fatty acids. Annals Nutrition Metabolism, v.43, p.127-130, 1999 .

SOUZA, M.L.R.; MARANHÃO, T.C.F. Rendimento de carcaça, filé e subprodutos da filetagem da tilápiado Nilo, Oreochromis niloticus (L), em função do peso corporal. Acta Scientiarum, Maringá, v.23, n.4, p.897901, 2001.

SOUZA, N.E.; STEVANATO, F.B.; GARCIA, E.E.; VISENTAINER, J.E.L.; ZARA, R.F.; VISENTAINER, J.V. Supplemental dietary flaxseed oil affects both neutral and phospholipid fatty acids in cultured tilapia. European Journal of Lipid Science and Technology, Weinheim, v.110, p.707-713, 2008.

STANSBY, M.E. Introduction in fish oils in nutrition. In: STANBY, M.E. Fish oils in nutrition. New York: V.N. Reinhold, 1990. 313p.
STANSBY, M.E.; HERMANN, S.; GRUGER JUNIOR, E.H. Fatty acid composition of fish. In: STANBY, M.E. Fish oils in nutrition. New York: V.N. Reinhold, 1990. 313p.

STASOFT. Statistica. Version 5.0. Tucksa, 1995.

Software.

STEVANATO, F.B.; PETENUCCI, M.E.; MATSUSHITA, M.; MESOMO, M.C.; SOUZA, N.E.; VISENTAINER, J.E.L.; ALMEIDA, V.V.; VISENTAINER, J.V. Avaliação química e sensorial da farinha de resíduo de tilápias na forma de sopa. Ciência e Tecnologia de Alimentos, Campinas, v.27, n.3, p.567-571, 2007.

TONIAL, I.B.; STEVANATO, F.B.; MATSUSHITA, M.; SOUZA, N.E.; FURUYA, W.M.; VISENTAINER, J.V. Optimization of flaxseed oil feeding time lenght in adult Nile tilapia (Oreochromis niloticus) as a function of muscle omega- 3 fatty acids composition.

Aquaculture Nutrition, Cingapura, v.15, p.564-568, 2009.

VISENTAINER, J.V.; MATSUSHITA, M.; SOUZA, N.E.; CATHARINO, R.R.; FRANCO, M.R.B.

Composição química e de ácidos graxos em tilápias (Oreochromis niloticus) submetidas à dieta prolongada. Revista Nacional da Carne, São Paulo, v.3, p.109-112, 2003. 